\title{
A reinvenção globalizada dos territórios criativos: do contexto global ao nacional
}

The globalized reinvention of the creative territories:
from the global to the national context

Caio Cesar Marinho Rodrigues de Souza [I]

Gerardo Silva [II]

Resumo

0 presente artigo debate como a economia criativa, fenômeno econômico do final do século XX, que utiliza as forças da cultura atrelada a tecnologia e inovação, está reconfigurando os espaços das cidades. Para analisar tais desdobramentos nos territórios urbanos, este estudo traçará um paralelo histórico do contexto global ao nacional, analisando como tais ações ocorrem, configurando a dinâmica global dos "territórios criativos". Nesse sentido, o cenário brasileiro da economia criativa também é problematizado, tanto do ponto de vista institucional como do territorial. Por fim, o artigo busca compreender e refletir qual é a importância da economia criativa dentro das discussões atuais sobre 0 desenvolvimento dos territórios urbanos, em particular metropolitanos, e entender as perspectivas e os conflitos que ela determina nessas localidades.

Palavras-chave: economia criativa; territórios; trajetórias globais; implicações nacionais.

\begin{abstract}
This article discusses how the creative economy, an economic phenomenon from the end of the 20th century that uses the forces of culture linked to technology and innovation, is reconfiguring the spaces of cities. To analyze such developments in urban territories, this study will draw a historical parallel between the global and the national context, analyzing how such actions occur and configure the global dynamics of "creative territories". In this sense, the Brazilian creative economy scenario is also problematized, from an institutional as well as a territorial point of view. Finally, the article seeks to comprehend the importance of creative economy within current discussions on the development of urban territories, particularly metropolitan ones, and to understand the perspectives and conflicts that it determines in these localities.
\end{abstract}

Keywords: creative economy; territories; global trajectories; national implications. 


\section{Introdução}

Um território central, antes pouco atrativo, agora concentra na calçada o show de uma banda e atrai um aglomerado de pessoas, que o prestigiam mesmo que momentaneamente. $\mathrm{Na}$ outra esquina, um andaime com diversos artistas grafitando cores em prédios gigantescos, antes reconhecidos por sua velha cor cinza, oferece um novo olhar para as mudanças. Na quadra seguinte, um café-bar gourmet, decorado com parede "instamagrável" e com cardápio assinado por chefs famosos - participantes de programas gastronômicos da televisão, youtube e instagram -, causa uma movimentação de pessoas para a região, ao som de tropicalidades brasileiras. 0 cenário descrito poderia ser um roteiro de uma cena de série ou filme americano, mas é um exemplo do novo cotidiano em diferentes centros urbanos mundiais, tais como São Paulo, Rio de Janeiro, Recife, Fortaleza, Nova York, Chicago, Londres, Bogotá, Buenos Aires, etc. Esse processo de revitalização e dinâmica urbana busca por investimentos: nacionais e internacionais, público ou privado, a fim de alterar a imagem daquele território e atrair e fixar um novo público-alvo.

Caminhar pelas ruas e centros dessas cidades, com efeito, traz constantes possibilidades de atinar-se com uma apresentação artística ou manifestação cultural nos espaços públicos ou com uma grande gama de espetáculos e equipamentos culturais, muitos deles com arquiteturas impressionantes (tradicionais, modernas e pós-modernas) que se tornam uma marca registrada e símbolo dessas cidades. Assim, esses territórios urbanos passam a concentrar criatividade e cultura, buscam desenvolver, nesses nichos, um fator de atração de diversidade e de diferentes classes profissionais em meio às dinâmicas recentes de transformação das cidades globais, vinculadas às evoluções no campo da produção e do trabaIho - imposto ou naturalmente desenvolvido. A cultura e a criatividade metamorfosearam-se em uma das principais características das transformações que os territórios urbanos vêm apresentando como ativos das cidades desde as últimas três décadas do século XX e, sobretudo, no início deste novo século, que já têm encaminhadas suas primeiras duas décadas.

Desde o final dos anos 1960 e início dos anos 1970, a discussão em torno da "culturalização"1 (vamos assim denominar, com base na referência de George Yúdice, 2003, o processo em que a cultura ganhou evidência e destaque nas políticas econômicas) de determinados territórios dentro das cidades, com maior relevância nos Estados Unidos e Europa, deve-se principalmente ao fato de diversos territórios começarem a sofrer cenários de evasão e quebra de setores industriais tradicionais. Esse fenômeno causa os chamados vazios urbanos, espaços que antes abrigavam um determinado setor industrial e produtivo, dotados de infraestruturas e que depois se esvaziaram e ficaram abandonados em meio ao cenário urbano fenômeno que causa tanto a perda da função produtiva como a degradação da paisagem.

Inicialmente, a principal estratégia seguida por alguns governantes, para reverter esse esvaziamento, foi a de adotar o sistema de desenvolvimento de novas centralidades na cidade, ou seja, utilizar a cultura como eixo estratégico do novo desenvolvimento e ressignificação do espaço urbano, marcando "[...] a passagem da estratégia modernista, anterior a esse processo, a uma atmosfera pós-moderna de lazer". De acordo com Harvey (1992), 
a lógica pós-moderna presente nesses projetos urbanísticos de renovação não representava [...] uma ruptura histórica significativa com a modernidade, mas sim uma etapa cultural representativa do capitalismo de acumulação flexível. Em outras palavras, significa uma intervenção urbanística adequada a nova ordem econômica. (Apud Frúgoli Junior, 2000, p. 22)

Como forma de efetivar essa estratégia, esses territórios passaram a ter novas formas de ocupação por setores voltados à cadeia do comércio e aos serviços e pela busca da inserção do desenvolvimento turístico, dando uma dinâmica para essas novas centralidades. Fatores que auxiliaram nos desdobramentos dessas características específicas recém-adquiridas e, assim, possibilitaram um dinamismo de ofertas de opções de entretenimento, lazer, cultura e consumo; além da possibilidade de explorar imobiliariamente tais centralidades criadas.

Assim, a necessidade de atenuar problemas socioeconômicos somada à união de setores públicos e privados e às "expectativas exageradas em se tratando da capacidade da cultura em compensar a diminuição dos empregos perdidos" (Krätke 2011, p. 22) tornaram-se fatores complementares para a criação de políticas públicas calcadas na regeneração do espaço urbano através da cultura. Esta regeneração, também tida como "revitalização, reabilitação, revalorização, reciclagem, requalificação, renascença" (Arantes 2002, p. 31), tinha como objeto principal a modificação da imagem de áreas estratégicas da cidade, de modo a trazer visibilidade e atrair novos visitantes e turistas, reaquecendo as economias locais. (Seldin, 2017, p. 45)

À vista disso, a cultura começou a ganhar papel e poder de modificar grandes áreas, trazer investimento de capital estrangeiro e, ao mesmo tempo, atrair potencial turístico, especulativo e de transformação para as cidades a partir do final dos anos 1970 e decorrer dos anos 1980 e 1990. Esse importante artifício se deu por conta das estratégias neoliberais de "mercadotecnia das cidades", ou seja, a função dos governos de vender as imagens das cidades pela atribuição da lógica do espaço-mercadoria à cidade-mercadoria (Sanchéz, 2010, p. 41), com o objetivo de, assim, inserir novas dinâmicas e setores produtivos, "decorrentes de uma nova revolução científico-tecnológica, do advento de um novo estágio do modo de acumulação capitalista e da instauração de uma nova ordem mundial" (Sant'Anna, 2017, p. 21), apelando para a transformação em prol do capital financeiro e tecnológico, colocando a cultura como eixo e política central para esse novo processo urbano que ali se protocolava, para fortalecer o "[...] empresariamento dos governos de cidade, à construção do civismo urbano e à espetacularização dos projetos de renovação" (Sanchéz, 2010, p. 41). Dessa forma, são iniciados os pressupostos da "culturalização" nas cidades.

Mas em que consistia a ideia de melhorar a imagem das cidades através de sua cultura ou da evidência dela? Diversos gestores urbanos do final do século XX canalizaram a cultura em um meio de explorá-la e inseri-la como atividade fim no lócus dos processos de regeneração urbana. Para entender esse movimento adotado pelos gestores urbanos, parte-se do pressuposto apresentado por Bauman, de que "[...] a 'cultura'² entrou no vocabulário moderno como uma declaração de intenções, o nome de uma missão a ser empreendida. $O$ conceito de cultura era em si um lema e um apelo à ação" (2013, p. 13). Como muito da formação e construção do Estado-nação e das cidades se dá por meio 
da influência de uma classe mais abastada e detentora de "conhecimento" e de uma "cultura mais elitizada", acreditava-se que, dentro das políticas urbanísticas, a vertente da cultura seria capaz de doutrinar e gerar as influências nos sistemas locais.

Nos anos seguintes às décadas de 1970 e 1980, "as políticas públicas foram formuladas de modo a atrair investimentos privados para o desenvolvimento dos centros urbanos, utilizando o discurso de que a demanda por serviços seria impulsionada, os gastos aumentariam e novos empregos seriam criados (Lees, Slater e Wyly 2008, p. xvii)". Dentro dessa lógica, houve um incentivo especial em serviços conectados às atividades culturais, turísticas e de entretenimento, o que levou à construção de centros culturais e de convenções, novos estádios esportivos e espaços para festivais e feiras. Além disso, novas alianças políticas foram formadas, como a união do poder público ao capital privado e a transformação do papel das agências de desenvolvimento econômico e elites de negócios em coordenadoras de campanhas de marketing urbano - uma atividade capaz de transformar e vender as cidades através de sua imagem como centros pós-industriais de serviços, lazer e consumo (Colomb, 2012 apud Seldin, 2017, p. 45).

A relação então estabelecida, de colocar a cultura dentro de uma lógica institucionalizada de políticas públicas, a partir de um modelo cultural mais elitista e orientado ao consumo, fez com que muitas cidades tivessem um boom de revitalizações e áreas ressignificadas dentro da lógica da "culturalização", começando a modelar a população para o consumo de uma Indústria Cultural e a massificação das identidades. Identidades estas que seriam alvo, nas décadas seguintes, de uma "objetificação" e desejo através de extensivas campanhas de marketing das cidades. A consequência desse processo de revitalização e dinâmica se justificava pela "culturalização" e criatividade. De um lado, ocorre uma movimentação insurgente e natural que reaviva o território através da música, arte e gastronomia. De outro lado, existe um processo de especulação imobiliária e gentrificação, alimentado pelo capital neoliberal e sob os mesmos pressupostos de cultura e criatividade.

Como dissemos, essa absorção, valorização e, principalmente, a democratização do acesso cultural nas cidades viraram uma pauta de discussões e reflexões em um período mais recente na história da urbe, por parte tanto dos governantes como de suas populações. Dessa forma, a "culturalização" transformou-se em uma importante estratégia de melhoria da qualidade de vida e promoção das cidades para atração de investimentos - locais, nacionais e principalmente internacionais - e passou a influenciar desde a cadeia industrial até a do turismo, entre outras. Nesse sentido, este artigo busca compreender como essa nova economia, que utiliza as forças da cultura atreladas a tecnologia e inovação, denominada "economia criativa", está reconfigurando os espaços das cidades e utilizando-se de estratégias através do turismo, passando do cenário global até o cenário brasileiro. 


\section{0 avanço das políticas de planejamento cultural estratégico e marketing urbano- o caso das capitais de cultura}

As estratégias de inserção da cultura transformaram-se em um modelo audacioso orientado ao marketing das cidades ou também chamado de city marketing, ${ }^{3}$ através do qual, para recuperar a imagem e os espaços vazios, cidades começaram a investir na requalificação pelo uso da cultura, vinculada ao lazer e ao turismo, impulsionada pelo contexto político e econômico neoliberal do período dos anos 1980 em diante. Essas cidades começaram, então, a investir tanto na economia de consumo, como na cadeia das indústrias culturais, construção de imagens que seriam possíveis de comercializar. Mas o que seriam essas imagens possíveis de comercializar? 0 incentivo à construção de museus, centros culturais, espaços de entretenimento e obras "espetacularizadas" assinadas por grandes arquitetos mundiais eclodia a cada ponto nas mais distintas cidades europeias e americanas. Ou seja, a ideia fundamental dessas estratégias era construir uma grande vitrine de venda das imagens das cidades, colocando-as, assim, em um contexto global de evidência e internacionalização urbana.

Nesse sentido, implementar as políticas de valorização da imagem tornou-se uma obsessão em muitas das cidades europeias e norte-americanas no início da década de 1980. Nesse período, um dos principais projetos e de maior sucesso relacionados ao city marketing foi lançado, o programa da União Europeia chamado Capitais da Cultura, com a abreviação de ECoC (European Capital of Culture). Lançado em 1985, o programa teve um sucesso exponencial, pois diversas cidades da UE (União Europeia) aplicaram-se para obter o título. Como função básica, a iniciativa da União Europeia tem como objetivo principal a promoção de suas cidades; aquelas que recebem o título de Capital da Cultura desenvolvem, durante o período de um ano, atividades relacionadas à cadeia das indústrias culturais e que permitem a interação de turistas, sejam eles domésticos ou internacionais, com a cultura local, para promover e propagar os seus conhecimentos imateriais, além da promoção da imagem em um ambiente internacional.

\begin{abstract}
A premiação, que implicava a realização de uma série de eventos culturais apoiados por um forte marketing urbano, objetivava assumidamente os seguintes pontos: ressaltar a riqueza e diversidade das culturas europeias, fomentar a contribuição da cultura para o desenvolvimento urbano, regenerar as cidades, elevar seu o perfil internacional, engrandecer a imagem das cidades aos olhos de seus próprios habitantes e aumentar o turismo. A partir de 1999, o título foi modificado para "Capital de Cultura Europeia" e, poucos anos depois, a premiação foi enquadrada como parte das políticas de criatividade incentivadas pela EU. (Seldin, 2017, p. 51)
\end{abstract}

Receber o título de uma ECoC, além da relação com a imagem, vinculava, ao ideário de seus administradores, a possibilidade de atração de recursos e de investimentos financeiros, oriundos tanto da UE, como de setores privados e fundos internacionais. Estes variam desde uma demanda local e doméstica até os públicos internacionais dentro da Europa e fora do continente, atrelando ao poder do city marketing o fator necessário para atração de capital financeiro de investimento e também de turistas. 
Tanto se faz evidenciar essa preleção da cultura como o fator de mudança da imagem e atração de investimentos, que, dentro dos principais resultados buscados pelas cidades que obtinham o título de Capital da Cultural, as atividades culturais eram consideradas catalisadoras, conforme descritas no Gráfico 1 e nas informações extraídas no relatório da UE sobre as ECoC. Assim, os principais objetivos esperados eram (European Union, 2021, p. 114):

- destacar a riqueza e a diversidade das culturas na Europa;

- comemorar as características culturais que os europeus compartilham;

- aumentar o sentimento de pertencimento dos cidadãos europeus a um espaço cultural comum;

- fomentar a contribuição da cultura para o desenvolvimento das cidades.
Além disso, a experiência ao longo das décadas tem demonstrado que o título de ECoC é uma excelente oportunidade para:

- promover a regeneração das cidades;

- elevar o perfil internacional;

- aprimorar a imagem das cidades aos olhos de seus próprios habitantes;

- dar respiro à nova vida à cultura de uma cidade;

- impulsionar o turismo;

- desenvolver o turismo;

- melhorar as percepções externas da cidade, geralmente para fins econômicos;

- apoiar o crescimento de novas indústrias, seja para diversificação ou substituição de indústrias recuadas;

- possibilitar o engajamento social, inclusive estimulando o orgulho na cidade;

- regeneração física.

Gráfico 1 - Benefícios esperados de curto e longo prazo, referentes a participação e recebimento do título de ECoC

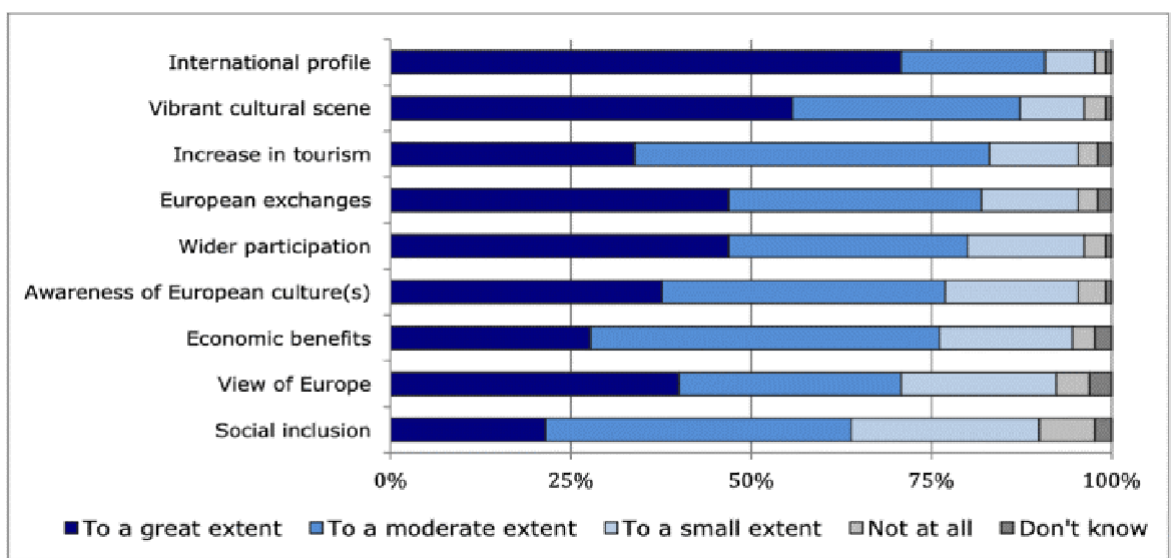

Fonte: European Union (2013, p. 114). 
Fica claro, através das expectativas das cidades participantes das ECoCs, e não muito complicado de analisar, através do gráfico apresentado, que de fato a cultura ou "culturalização" dos territórios e cidades pretendia ser utilizada como uma possível "fórmula-mágica" do desenvolvimento de atrativos culturais e regeneração de territórios nas cidades que obtinham o título. Essas práticas foram disseminadas de forma muito rápida e foram muito bem recebidas por gestores urbanos de outras cidades do final do século XX.

A questão da regeneração urbana é descrita como uma das principais intenções e motivações pelas quais muitas cidades buscavam o título de ECoC diversas vezes, o que reafirma o ponto apresentado pela autora Fernanda Sánchez (2010), referente aos interesses globais e das políticas focadas no marketing urbano, dentro do documento da União Europeia. É possível destacar as seguintes passagens do documento que evidenciam a tendência da regeneração urbana e o desenvolvimento turístico como uma das atividades foco nos projetos desenvolvidos:

I - Outro objetivo enfatizado pelas cidades licitantes é conceituado dentro da ambição de a ECoC ser um "catalisador" para mudanças em outras áreas, como o desenvolvimento do turismo; aumento do investimento interno; apoio ao crescimento de novas indústrias; regeneração física; engajamento social e maior orguIho da cidade. (p. 15; tradução nossa)

III - Indiscutivelmente, o reconhecimento formal e a expectativa de que o $\mathrm{ECoC}$ "seja uma oportunidade valiosa para regenerar cidades, elevar seu perfil internacional e impulsionar o turismo" [...] No entanto, também abriu novas áreas de preocupação, em comum com outras estratégias estabelecidas de regeneração, lideradas por eventos e pela cultura. (p. 51; tradução nossa)

Com o êxito do modelo das ECoCs, a realidade de atrair e aumentar a quantidade de grandes eventos internacionais, construir prédios sob a assinatura de arquitetos de renome ou renovar/regenerar áreas inteiras somente para as práticas de comercialização, turismo e atratividade cultural, não se restringiu somente às cidades norte-americanas ou europeias, mas foi disseminada em diversos cantos do mundo.

Por meio de diversas tendências, perfila-se esta estratégia global: a concretização no território da chamada "sociedade de consumo dirigido", a apresentação das cidades renovadas como centros de consumo privilegiado, a imposição de uma ideologia da felicidade graças ao consumo e graças a um urbanismo adaptado à sua nova missão, a edificação dos centros de decisão, concentradores dos meios de poder: informação, organização, operação e persuasão (ideologia e publicidade). Nesse contexto, não basta renovar as cidades, é preciso vendê-las e, ao fazê-lo, vende-se a imagem da cidade renovada. (Sanchez, 2017, p. 50)

Com isso, entende-se que a questão da "culturalização" e "turistificação" das cidades e de seus espaços se tornou parte de uma grande agenda mundial de desenvolvimento e passou a ser uma estratégia amplamente divulgada e praticada, um alvo de gestores urbanos que queriam criar marcas em sua gestão e tentar de alguma forma deixar um legado para as cidades. Entretanto, vale ressaltar que o modelo podia ser uma "faca de dois gumes". Mas, apesar de poder afetar positivamente os processos, a regeneração, que era o principal 
objetivo para muitos governantes, normalmente tendia para a possibilidade de gerar processos de gentrificação, ${ }^{4}$ assim:

[...] diversos autores ressaltavam as consequências negativas resultantes da supervalorização de centros históricos e do desenvolvimento de projetos arquitetônicos espetaculares voltados para atividades de cultura, lazer e entretenimento, condenando a espetacularização e "cenarização" da paisagem, a gentrificação e a instrumentalização da cultura. Para eles, o uso da cultura nos projetos urbanos tinha como objetivo principal a construção de identidades urbanas artificiais, capazes de competir mundialmente e de atrair turistas e novos investimentos imobiliários passíveis de aquecer as economias locais em declínio, devido, principalmente, a intensos processos de desindustrialização ocorridos nos anos anteriores. (Seldin, 2017, p. 14)

Apesar do longo planejamento e da ainda atual existência do título de ECoC na EU e de seu modelo ter se replicado globalmente, já, no início dos anos 1990, era perceptível um provável esgotamento das práticas de "culturalização" das cidades através do título de capitais de cultura. Nesse período, começou então a ocorrer um movimento de mudança no discurso do planejamento das cidades. 0 foco migrou para o desenvolvimento de um novo setor econômico, que combinava tecnologia, serviços e a área da cultura, um dos principais segmentos para a regeneração econômica de algumas cidades na Austrália e no Reino Unidos no princípio da década de 1990. Tal fenômeno se tornou em pouco tempo um novo case de sucesso e chamou a atenção de diversos pesquisadores e gestores urbanos.

\section{Do desenvolvimento da economia criativa à interação com os território urbanos}

Já no início dos anos 1990, o modelo de sucesso das Capitais de Cultura e aparelhamento das indústrias culturais começará a mostrar alguns ruídos e a entrar em um processo de detrimento. Uma evolução ocorre em suas estratégias através do surgimento e da eminência dos conceitos da classe, economia e indústrias criativas empregados pelas teorias do norte-americano Florida (2002), baseado na teoria dos 3 Ts (Tecnologia, Talento e Tolerância), que principiavam a interagir com o espaço urbano e atribular seus principais fatores de desenvolvimento. $\mathrm{O}$ autor investiga se esta também se tornaria uma nova estratégia de financiamento e marketing urbano, evidenciando a busca/ corrida das cidades para atrelarem à fórmula dos 3 Ts em suas realidades e, também, para tentarem obter o título de "cidade/território criativa(o)" criado por grandes agências internacionais como a Unesco e sua Rede de Cidades Criativas.

Ou seja, o que ocorreu se configurou como um aperfeiçoamento estratégico e necessário das Indústrias Culturais, ${ }^{5}$ que somente abarcavam setores da cultura, para as Indústrias ditas "Criativas", uma nova cadeia e economia mais robusta e interligada com outros setores de forte desenvolvimento e atração de capital para o início e demandas do século XXI.

A Unctad (Conferência das Nações Unidas sobre Comércio e Desenvolvimento), vinculada à ONU (Organização das Nações Unidas), desde o eminente fortalecimento 
das teorias das indústrias criativas, começou a abarcar e a propor relatórios específicos e destinados à temática, apresentando uma nova compreensão e metodologia quanto às indústrias criativas, ao concentrá-las em 4 áreas principais. São elas: 1) Patrimônio, que abarca áreas como lugares culturais (sítios arqueológicos, museus, bibliotecas, exibições, etc.) e tradições e expressões populares (artesanato, festas populares, etc.); seguindo por 2) Artes, compreendendo, artes visuais (pinturas, esculturas, fotografia e antiguidades), artes performáticas (shows, teatros, dança, cinema, ópera, etc.). Outro setor por eles definidos é o de 3) Mídia, que relaciona a parte de publicações e mídia impressa (livros e publicações), audiovisual (filme, televisão e rádio), design (interiores, gráfico, joalheria, moda, brinquedos, etc.) e novas mídias (softwares, videogame e conteúdos digitais). Por final, o setor de 4) Criações Funcionais, composto por uma área denominada serviços criativos (arquitetura, publicidade e propaganda, pesquisa e desenvolvimento, recreação, etc.).

Apesar de a EC (Economia Criativa) apresentar uma certa complexidade em sua definição, é um fato que a criatividade está presente e é constantemente implementada em diferentes dimensões (científica, econômica, cultural, tecnológica, etc.), o que permite o seu fortalecimento. Para comprovar essa informação, importantes dados econômicos mundiais, desde a estratégia do governo britânico de Tony Blair (Partido Trabalhista 1997-2007) até os dias atuais, demonstram crescimento do destaque da EC dentro das discussões econômicas globais durante estas duas décadas do século XXI. De tal modo, ela ganha atenção e destaque dentro de diversas políticas de reformulação de estratégias e posicionamento no mercado financeiro mundial e nas cadeias a serem investidas nas próximas décadas.

Dentro de todas essas características, as indústrias e a economia criativas, desde 1997, demonstram um acelerado crescimento, pouca recessão em relação a outros mercados, e disseminação e implementação em diversos países que passaram a adotá-las. Entre os anos de 2002 e 2015, o relatório Creative Economy Outlook: Trends in international trade in creative industries - 2002-2015, desenvolvido pelas Nações Unidas através da Unctad, demonstrou uma intensa e contínua evolução da EC. Ela é responsável por números como os demonstrados através de "[...] dados disponíveis que mostram que as exportações mundiais mais que dobram de US\$208 biIhões em 2002 para US\$510 bilhões em 2015, enquanto as importações quase dobram de US\$227 bilhões em 2002 para US\$454 bilhões em 2015, gerando um superávit comercial de US\$55 bilhões em 2015" (Unctad, 2018, p. 23; tradução nossa).

Em seu conhecido trabalho, $A$ ascensão da classe criativa, Richard Florida (2002) investigou como a economia criativa interagia com o desenvolvimento de uma nova classe trabaIhadora dentro das lógicas das sociedades pós-industriais. Dessa forma, a economia criativa, ao relacionar-se com determinado território, tende a modificar bruscamente as realidades e dinâmicas das cidades globalmente e busca atribuir e agregar novas potencialidades de atratividade para um desenvolvimento econômico próspero para o século XXI.

Faz-se necessário ressaltar que o movimento reafirmado por Florida, de utilizar a cultura e o turismo como estopim de um processo de renovação urbana, entra na mesma 
lógica demonstrada em diversas cidades ao redor do mundo durante as décadas de 1970 até 1990, já afirmadas anteriormente, que almejaram a requalificação dos vazios urbanos, a posteriori, com a busca do título de "capital de cultura". Desse modo, é demonstrado um grande alinhamento e investimento de setores ligados a economia e indústria da cultura, marketing urbano e desenvolvimento de novas atratividades turísticas, necessitando, assim, que as estratégias anteriores migrassem para um novo ideal já na década de 1990 e início do século XXI. Destarte, são criadas medidas de desenvolvimento urbano voltadas para a economia criativa, ponto que viria a esquentar as discussões durante esse período e ganhar amplo campo para debates a respeito dos conflitos e gentrificações que passaram a ocorrer, nem sempre possibilitando a criação do desenvolvimento urbano, social e próspero, que o Manifesto de Memphis mencionava:

Comunidades criativas são lugares vibrantes e acolhedores que fomentam o desenvolvimento pessoal, estimulam avanços tecnológicos e culturais, geram empregos e prosperidade, além de aceitarem culturas e estilos de vida diversos. (Florida, 2002, p. 381)

Dessa forma, Florida aborda o processo de introduzir a questão da economia criativa e a classe criativa nas lógicas dos territórios urbanos, sem deixar de evidenciar que é necessário que as cidades de todo o mundo se atentem para essa nova economia e para os indivíduos que a compõem. Assim, muitos governantes passaram a desenvolver propostas urbanas voltadas aos interesses de agrupamento desses indivíduos em diversas localidades da cidade, a fim de estimular o desenvolvimento das potencialidades de atração desses "criativos" e, em paralelo, a melhoria dos espaços das cidades, através de renovações, ressignificações e revitalizações.

Florida estabelece, em sua teoria, que, para uma localidade conseguir atrair membros da classe criativa e se tornar de fato uma cidade/distrito criativa(o), é necessário o desenvolvimento de 3 Ts: o primeiro T de Tecnologia, o segundo de Talento e o terceiro de Tolerância. "Cada uma dessas condições é necessária, mas sozinha é insuficiente: para atrair indivíduos criativos, gerar inovação e estimular o crescimento econômico, um lugar precisa reunir as três" (ibid., p. 249).

Para conseguir o desenvolvimento dos 3 Ts de Florida, é necessário desenvolver a teoria do capital criativo, que se fundamenta na ideia de que:

[...] o crescimento econômico regional é impulsionado por pessoas criativas, que preferem lugares diversificados, tolerantes e abertos a novas ideias. A diversidade aumenta o potencial do lugar de atrair vários tipos de indivíduos criativos, com ideias e habilidades distintas. Lugares com misturas diversas de pessoas criativas são mais propensos a gerar novas combinações. Sem falar que a união de diversidade e quantidade acelera o fluxo de conhecimento. Quanto maior e mais diversificada a concentração de capital criativo, maior também a capacidade de inovar, de criar negócios de alta tecnologia, de gerar empregos e de crescer economicamente. (Ibid.)

Conforme o trecho apresentado, dado o crescimento da economia criativa como fator e eixo de desenvolvimento econômico, a atração da classe criativa e sua concentração dentro de determinados territórios, junto à absorção da cultura e criatividade, alinhado à lógica do capital social criativo, contemplando 
o desenvolvimento dos 3 Ts, tornaram-se uma estratégia passível de acontecer e ser implementada dentro dos planos de desenvolvimento urbano. Isso porque um dos principais argumentos, dentro da possibilidade de desenvolvimento de uma "cidade criativa", é que cidades, bairros e territórios capazes de entender suas singularidades e cultura conseguem estabelecer um vínculo de atração aos membros da classe criativa, podendo, então, gerar os espaços urbanos voltados ao estímulo da criatividade, inovação e cultura, denominados "bolsões ou clusters ${ }^{6}$ criativos".

A economista Ana Carla Fonseca Reis alude, no estudo Cidades criativas - Perspectivas (Reis e Urani, 2011), desenvolvido junto a 18 autores de 13 países diferentes, a possibilidade de perceber e identificar a existência de 3 características que efetivamente traçam uma cidade criativa, além da já mencionada teoria dos 3 Ts de Florida. Independentemente de sua escala, de sua história ou de seu contexto socioeconômico, uma cidade que busca ser criativa necessita ter Inovação (inovações tecnológicas, sociais e culturais), formas diferentes de ver muitas vezes o que já estava lá, mas ninguém percebia, que se alinha aos Ts da Tecnologia e Talento. A segunda característica é representada pelas Conexões (conexões entre áreas da cidade, conexões entre público e privado, conexões entre local e global) entre diversidades que convivem em um espaço público, aqui podemos colocar o T da Tolerância. Por fim, a Cultura, pelos seus valores simbólicos, cultura pelo seu impacto econômico (manifestações, produtos, serviços) e, também, pelo ambiente criativo que ela gera em nossas cidades.

Através das 3 características apresentadas para o desenvolvimento de uma cidade criativa (Inovação, Conexão e Cultura) e a fórmula dos 3 Ts de Florida, diversos gestores urbanos passaram a tratar como eixos centrais o desenvolvimento e a permissão de manifestações e ocupações criativas em determinados territórios de suas cidades. Isso fez com que as pessoas recriassem vínculos e identidade com aqueles determinados locais de seu dia a dia ou evidenciassem possíveis diferenciais em meio ao cenário cinza da urbe. Dessa forma, elas passam a se deparar com momentos diferentes e não habituais (ex: uma banda tocando na esquina, um grafite ao ar livre, um festival acontecendo no espaço público, etc.), capazes de gerar uma qualidade de vida e um estímulo à criatividade e ao turismo.

\section{Estratégias e políticas da economia criativa no contexto brasileiro}

É fato inegável que o Brasil possui uma cultura rica, em sua diversidade, história e criatividade. Uma cultura que, por assim dizer, é plena de identidade, singularidade e beleza. O Brasil tem na sua cultura, com efeito, um fator potencial de desenvolvimento de suas riquezas. Como Celso Furtado já dizia, e que doravante temos como pressuposto, "a reflexão sobre a cultura brasileira deve ser o ponto de partida para o debate sobre as opções de desenvolvimento" (Furtado, 2012, p. 34). A diversidade cultural presente na formação do brasileiro, desde as raízes indígenas e portuguesas, e da "miscigenação" que ocorrera durante séculos engendrou possibilidades significativas para o desenvolvimento da criatividade. É a partir das conexões entre diferentes culturas (um dos 
fatores necessários para o desenvolvimento da economia criativa) que novas características e oportunidades se originam, se inventam e se inovam e, assim, geram uma explosão de criatividade e de traços culturais particulares e mundialmente reconhecidos. ${ }^{7}$

0 relatório Visão 2035: Brasil, país desenvolvido - Agendas setoriais para alcance da meta, do BNDES (Banco Nacional do Desenvolvimento), que trabalha análises de 17 setores da economia brasileira por meio de cenários, para construir uma agenda de desenvolvimento para o período 2018-2035, analisou a economia criativa com um dos setores promissores. 0 documento indica que:

A tendência futura é de que o crescimento da indústria criativa permaneça acima do crescimento mundial, e o Brasil demonstra potencial ainda maior de crescer, o que reflete a dimensão do mercado doméstico, a criatividade para geração de novos produtos, conteúdos e serviços e a notória riqueza cultural brasileira, um dos mais importantes insumos de nossos produtos e serviços. No Brasil, as indústrias criativas e culturais também demonstram participação relevante na economia. $\mathrm{O}$ estudo mais conhecido sobre o tema, que chegou à quinta edição, é publicado periodicamente pela Federação das Indústrias do Estado do Rio de Janeiro (Firjan, 2016). Segundo estimativas do estudo, as indústrias criativas e culturais do Brasil foram responsáveis por gerar $\mathrm{R} \$ 155,6$ bilhões em 2015, o que representou 2,64\% do PIB brasileiro naquele ano. No mesmo ano, essas indústrias empregaram 851,2 mil pessoas, ou $1,8 \%$ do total de empregos formais no Brasil. A perspectiva de crescimento das indústrias criativas no Brasil é superior à média mundial. (Puga e Castro, 2018, pp. 262-263)
Dois outros relatórios demonstram a importância da economia criativa para o desenvolvimento econômico brasileiro, conforme apontado no relatório Creative economy outlook: trends in international trade in creative industries 2002-2015. Country profiles: 2005-2014, indica que "[...] As exportações de serviços criativos do Brasil somaram US\$1.808 milhões em 2014, lideradas por pesquisa e desenvolvimento com US\$525,1 miIhões; serviços de informática com US\$946,9 milhões; audiovisual e serviços relacionados com US\$265,4 milhões; e serviços de informação com US\$71,3 milhões" (Unctad, 2018, p. 98; tradução nossa). "Segundo o Global Entertainment and Media Outlook 20172021, estudo realizado pela Pricewaterhouse Coopers (PWC, 2017) para os segmentos da mídia e do entretenimento da economia criativa no mundo, essas indústrias brasileiras tendem a crescer, em média, mais aceleradamente que seus pares no mundo. A taxa de crescimento anual composta (CAGR) para os segmentos brasileiros é de $4,6 \%$ no período 2016-2021. Já, para o resto do mundo, esse crescimento é de 4,2\%" (Puga, 2018, p. 263).

Conforme as potencialidades apontadas, tanto dos avanços quanto dos prognósticos futuros pelo setor criativo, o Brasil começou a posicionar-se e dar maior atenção a esse eixo econômico, de fato, somente em 2011, através do Ministério da Cultura, que, na época, era administrado pela ministra Ana de Hollanda, na gestão da presidente Dilma Rousseff (PT). Ela criou a Secretaria de Economia Criativa (SEC), que tinha como objetivo central criar estratégias de implementação do setor no Brasil, através da "[....] formulação, implementação e monitoramento de políticas 
públicas para um novo desenvolvimento fundado na inclusão social, na sustentabilidade, na inovação e, especialmente, na diversidade cultural brasileira" (MinC, 2011, p. 1). Este é o principal marco, até os dias atuais, da formulação de políticas voltados ao campo da economia criativa no Brasil, por compor, além da criação da secretaria dentro do MinC, o desenvolvimento de um plano estratégico, o Plano Brasil Criativo (PBC), em vista da consolidação e da inserção das indústrias criativas como eixo estratégico de desenvolvimento brasileiro. Conforme trecho escrito pela ministra Ana de Holanda a respeito dos desafios da SEC e da importância da implementação e desenvolvimento do PBC:

Vinte e três anos da data de aprovação do texto final da nossa Constituição, o Ministério da Cultura vem lançar o Plano da Secretaria da Economia Criativa (2011-2014), a mais nova secretaria do MinC, no governo Dilma Rousseff. A economia criativa tem obtido destaque no foco das discussões de instituições internacionais como a Unctad (Conferência das Nações Unidas para o Comércio e o Desenvolvimento), o Pnud (Programa das Nações Unidas para o Desenvolvimento) e a Unesco (Organização das Nações Unidas para a Educação, a Ciência e a Cultura), sendo considerada um eixo estratégico de desenvolvimento para os diversos países e continentes, no novo século. [...] Por isso, nós, que fazemos o Ministério da Cultura, saudamos com alegria e esperança o Plano da nova Secretaria da Economia Criativa. Que esse documento simbolize um marco para o reposicionamento da cultura como eixo de desenvolvimento do País. Afinal, tal como Câmara Cascudo, nós também acreditamos que "o melhor do Brasil é o brasileiro". (MinC, 2011, p. 1)
Uma característica em comum tanto nas referências acadêmicas como dos governos é de buscar empregar a economia criativa como uma estratégia de desenvolvimento nacional, como forma de integração dos setores culturais e tecnológicos e como um viés de inclusão social e renovação econômica e urbana para um desenvolvimento próspero no século XXI.

A Secretaria da Economia Criativa, no MinC, baseou-se no modelo proposto pela Unctad, que concentra as atividades criativas dentro de 4 eixos principais (Patrimônio, Artes, Mídias e Criações Funcionais), para delinear o escopo dos setores criativos brasileiros. Desse jeito, estabeleceu uma relação de 5 categorias culturais principais que abrangeria os principais setores e cadeias criativas nacionais. Elas são:

- Patrimônio (materiais e imateriais, museus e arquivos);

- Expressões culturais (artesanato, artes visuais, culturas afro, indígena e populares);

- Artes e espetáculo (dança, música, circo e teatro);

- Audiovisual, livro e literatura (cinema e vídeo e publicações);

- Criações funcionais (moda, arquitetura, design e arte digital).

O desenvolvimento do PBC pode ser considerado o principal marco da tentativa de implementação da economia criativa no Brasil, ao promover o setor cultural de mero coadjuvante e limitado ao campo artístico e do patrimônio, para a tentativa de ser um dos principais setores de progresso e desenvolvimento econômico nacional. Ele é um plano criado junto os ministérios da Esplanada e com o objetivo de compreender a transversalidade dos setores que abrangem a cadeia da economia criativa e como ela poderia ser 
desenvolvida e implementada além das atribuições do MinC, fortalecendo um viés da economia criativa nacional.

A SEC tentou implementar a visão estratégica de uma adequação ao momento e tentou estabelecer métricas sólidas para o desenvolvimento de ações para a implementação da economia criativa como um eixo do desenvolvimento e reposicionamento brasileiro, de protagonista tanto no mercado sul-americano como no internacional. Para conseguir estabelecer essa nova visão, um planejamento intersetorial de programas e ações no âmbito do governo federal (Fluxograma 1) foi realizado para conseguir, dessa maneira, buscar frentes para efetivar as políticas nacionais da economia criativa. Foi feito um alinhamento com 16 ministérios, em busca de estabelecer e desenhar os processos da implementação e mapeamento das atividades e dos setores que dialogariam com essa política pública de inserção da economia criativa como nova vertente econômica para o Brasil.

Esse alinhamento com os mais diversos ministérios, focado na possibilidade de implementação da economia criativa como um novo setor essencial para o desenvolvimento econômico brasileiro nas mais diversas frentes, possuía como principais características: a visão de incentivar a sustentabilidade, a inovação e a diversidade, principalmente através do desenvolvimento de micro e pequenas empresas

Fluxograma 1 - Articulações intersetoriais da secretaria de economia criativa para efetivar as ações do PBC para o desenvolvimento da economia criativa como eixo estratégico no Brasil

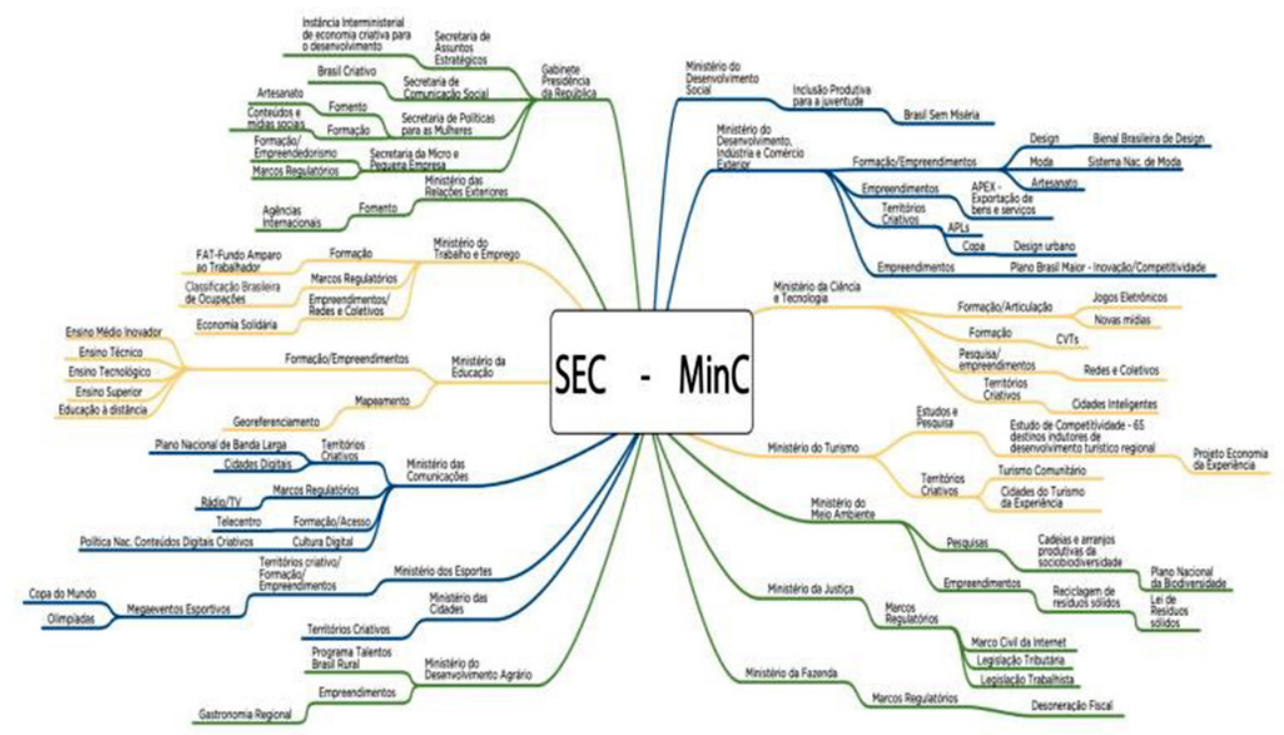

Fonte: MinC (2011, p. 57). 
e comunidades mais vulneráveis. Dentro do plano da Secretaria de Economia Criativa, o desenvolvimento da economia criativa foi tratado como principal ativo para o desenvolvimento da inclusão social.

Essa visão do modelo brasileiro de debater a economia criativa mostra um avanço diante das ideias mundialmente difundidas e implementas por Richard Florida. Apesar de ter certas consonâncias como as vertentes da diversidade cultural que se alinham com a questão da tolerância e a inovação ligada a tecnologia e talento, as vertentes de sustentabilidade e inclusão social mostram essa preocupação ante a complexidade brasileira. De certa forma, demonstram uma ideia de inserção da economia criativa, para além das estratégias voltadas ao capital, com a intenção de um desenvolvimento social por meio de capacitações de sua população e preservação do meio ambiente. Conforme a ex-secretária de Economia Criativa menciona:

Contudo, maiores do que os desafios relativos ao desenvolvimento da Economia Criativa brasileira eram (e ainda são) os riscos de reduzirmos a Economia Criativa ao domínio das indústrias culturais e, por conseguinte, à mera dimensão mercadológica dos seus bens e serviços. Por outro lado, a formulação e a implantação de políticas que o Ministério da Cultura, através da Secretaria da Economia Criativa, deveria liderar não poderiam nem deveriam se afastar do seu compromisso com o fortalecimento dos micros e dos pequenos trabaIhadores da cultura, o maior contingente de artistas, profissionais, empreendedores e gestores dos setores culturais e criativos, formais e informais, que fazem do Brasil um dos grandes "celeiros" da diversidade cultural e das tecnologias sociais do planeta. (Leitão e Machado, 2016, p. 331)
Dentro do plano da SEC, fica evidente que uma das principais ações para o desenvolvimento e efetivação da economia criativa estaria intrinsecamente voltada à questão da interação com o território através da estratégia denominada "territórios criativos", 8 conforme evidenciado nas estratégias de outros países, impulsionando o desenvolvimento cultural, criativo e turístico nesses territórios.

Territórios Criativos: Nesse campo, serão trabalhadas a concepção e a implementação de metodologias, ações, projetos e programas que permitam o surgimento e a institucionalização de territórios criativos (bairros, polos produtivos, cidades e bacias criativas). Serão prospectados espaços que tenham potencial para serem considerados territórios criativos e, dessa forma, possam potencializar a geração de trabalho, emprego e renda. (MinC, 2011, p. 41)

O que chama a atenção, na estratégia dos "territórios criativos" proposta pela SEC, está na forma de identificação desses territórios que compõem a "Rede de Cidades Criativas". Conforme explanado no trecho do documento que relata o que seriam esses territórios criativos, demonstra-se que o critério de seleção adotado seria em torno da prospecção de localidades que tivessem potencial para serem consideradas criativas e, dessa forma, pudessem potencializar a geração de trabalho, emprego e renda. Seriam esses potenciais um paradigma em torno da inclusão que a própria SEC pretendia estabelecer através da economia criativa?

Conforme demonstrado no Quadro 1 , cada Ministério teria uma função dentro das ações de implementação e consolidação dos "territórios criativos", sendo um ponto chamativo, vide modelos estrangeiros 
Figura 1 - A economia criativa brasileira e seus princípios norteadores

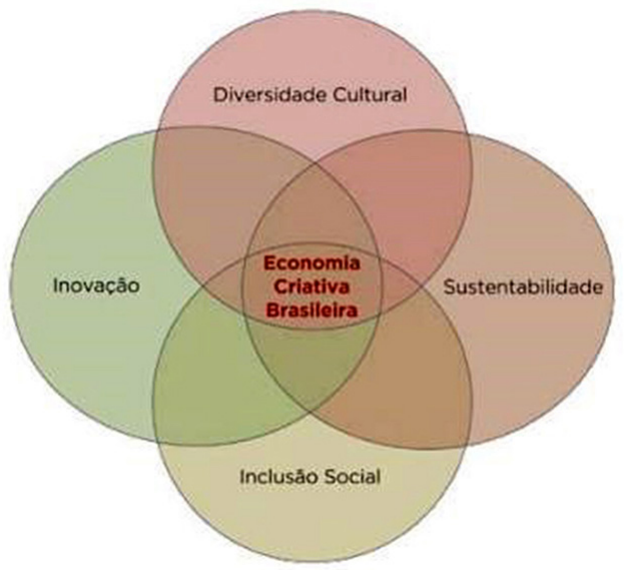

Fonte: MinC (2012, p. 33).

\section{Quadro 1 - Ações via Ministérios para institucionalização dos Territórios Criativos no PBC da SEC}

\begin{tabular}{|c|c|}
\hline \multicolumn{2}{|c|}{$\begin{array}{l}\text { Ações de desenvolvimento dos Território criativo dentro do Plano Brasil Criativo } \\
\text { da Secretaria de Economia criativa 2011-2014 }\end{array}$} \\
\hline Ministério/Instituições & Parceria/Alinhamento de programas federais \\
\hline Ministério dos Esportes & $\begin{array}{l}\text { Desenvolvimento de ações de qualificação dos territórios das cidades-sede da } \\
\text { Copa do Mundo e da cidade-sede das Olimpíadas }\end{array}$ \\
\hline $\begin{array}{l}\text { Ministério do Desenvolvimento, } \\
\text { da Indústria e Comércio Exterior }\end{array}$ & $\begin{array}{l}\text { Mapeamento de vocações regionais nas cidades-sede da Copa do Mundo e } \\
\text { qualificação dos espaços via design urbano }\end{array}$ \\
\hline $\begin{array}{l}\text { Ministério da Ciência } \\
\text { e Tecnologia - MCT }\end{array}$ & $\begin{array}{l}\text { Institucionalização de territórios criativos em articulação com o projeto Cidades } \\
\text { Inteligentes do MCT }\end{array}$ \\
\hline Ministério das Comunicações & $\begin{array}{l}\text { Implementação do Plano Nacional de Banda Larga no sentido de qualificar a } \\
\text { infraestrutura dos territórios criativos. Institucionalização de territórios criativos } \\
\text { em articulação com o projeto Cidades Digitais do Ministério }\end{array}$ \\
\hline Ministério das Cidades & Articular a institucionalização de territórios criativos \\
\hline Ministério do Turismo & $\begin{array}{l}\text { Em convergência com os projetos de Turismo Comunitário e Cidades do Turismo } \\
\text { de Experiência, articular e promover a institucionalização dos territórios } \\
\text { criativos }\end{array}$ \\
\hline $\begin{array}{l}\text { Instituto do Patrimônio Históri- } \\
\text { co e Artístico Nacional - IPHAN }\end{array}$ & $\begin{array}{l}\text { Fomentar e promover arranjos produtivos tradicionais vinculados a bens } \\
\text { tombados, registrados e/ou paisagens culturais (áreas protegidas pelo IPHAN } \\
\text { consideradas como territórios criativos por excelência, sem necessidade de } \\
\text { criação de novas categorias) }\end{array}$ \\
\hline $\begin{array}{l}\text { Fundação Biblioteca Nacional } \\
\text { - FBN }\end{array}$ & $\begin{array}{l}\text { Identificar a reconhecer territórios criativos e de arranjos produtivos por meio } \\
\text { da literatura, com a finalidade de fomentar processos de criação, edição, publi- } \\
\text { cação, distribuição, comercialização, formação e intercâmbios literários, musicais } \\
\text { e de artes visuais }\end{array}$ \\
\hline
\end{tabular}

Fonte: quadro desenvolvido por Caio Cesar M. R. de Souza, com base nos dados do Plano da Secretaria de Economia Criativa do Ministério da Cultura. 
antecessores, a proposta feita pelo Ministério do Desenvolvimento, da Indústria e Comércio Exterior - MDIC, na qual se colocam como ação o mapeamento de vocações regionais nas cidades-sede da Copa do Mundo ${ }^{9}$ e a qualificação dos espaços via design urbano.

De acordo com essa informação, pode-se identificar ao menos três modelos que foram adotados em cidades estrangeiras, que causaram grandes fatores de especulação imobiliária e posteriormente de gentrificação, sendo eles:

1) "Mapeamento de vocações regionais": buscando dar destaque para essas ações como fator de promoção e atração de investimentos, sendo um ponto que pode gerar externalidades positivas ou negativas;

2) "Cidades-sede da Copa do Mundo": o Brasil aguardava, naquele momento, a realização de megaventos que, conforme outras literaturas (Harvey, 2001; Reis, 2011; Sánchez, 2010; Seldin, 2017; Vivant, 2012), foram apontados como as principais estratégias para transformar grandes espaços urbanos; por final,

3) "Qualificação dos espaços via design urbano": nesse fator, entra uma questão importante para atentar-se devido ao melhoramento do espaço urbano através de um design aperfeiçoado ou, até mesmo, de globalização daquele espaço, por conta do contexto dos megaeventos, vide o caso do Porto Maravilha no Rio de Janeiro, com a arquitetura de espetacularização e globalizada do Museu do Amanhã, feita pelo arquiteto espanhol Santiago Calatrava.

Esses pontos demostram que, apesar de uma certa consonância com ações mais inclusivas propostas pelos demais Ministérios (Fluxograma 1) e por levar em consideração as particularidades e os desafios dos aspectos regionais brasileiros (Quadro 2) que integravam a ação de implementação, o MDIC vinha com uma proposta com um viés bastante reconhecido de implantação do conceito de territórios criativos. E, apesar do sucesso que muitas cidades obtiveram com esse modelo, efeitos negativos também ocorreram, como os já apontados de especulação imobiliária e gentrificação, o que acaba determinando uma perspectiva mais elitista para o consumo daqueles espaços em detrimento dos saberes e fazeres locais e até mesmo das populações que ali vivem.

Como as políticas de revitalização urbana são muitas vezes colocadas em práticas em bairros que estão conhecendo um processo espontâneo de gentrificação [...], com o tempo, essas políticas acentuam o processo de revalorização imobiliária inaugurado pela gentrificação espontânea e provocam uma mudança na população, que acaba por sufocar o caráter boêmio do setor e conduzir à expulsão dos artistas e dos primeiros gentrificadores. A produção da cidade pela classe criativa exclui a parcela boêmia e tende a inibir a criatividade em lugares promovidos como criativos. A pretensão de programar e promover revela desconhecimento das instâncias da serendipidade, condição de expressão da criatividade. (Vivant, 2010, p. 82)

Assim, um alerta deve ser feito sobre as formas de implantação e estratégias em torno do contexto de territórios criativos e sobre o desafio da coerência de pensamentos no campo da inclusão social, a fim de não causar uma parcela de "exclusão social" em prol do capital financeiro e da atração de turistas. 
Quadro 2 - Institucionalização dos territórios criativos por região geográfica do Brasil e suas particularidades

\begin{tabular}{|c|c|}
\hline \multicolumn{2}{|r|}{ Eixo - Territórios Criativos } \\
\hline Região & Estratégias \\
\hline Norte & $\begin{array}{l}\text { - Articular parcerias para institucionalizar territórios criativos a partir da potencialização das } \\
\text { vocações culturais da Região Norte. Exemplo de alguns recortes territoriais: Jalapão/Tocantins } \\
\text { (artesanato/capim dourado); Rio Branco: destino indutor de turismo histórico-cultural; Manaus } \\
\text { (ópera) e Itacoaraci/PA (cerâmica marajoara) }\end{array}$ \\
\hline Nordeste & $\begin{array}{l}\text { - Criação de programas, projetos e metodologias que facilitem a viabilização dos territórios } \\
\text { criativos. Exemplo de alguns recortes territoriais: Bairro da Madre Deus, São Luis/MA (festejos } \\
\text { populares) } \\
\text { - Levantamento e fomento de territórios e de experiências existentes; criação de redes de } \\
\text { espaços criativos a partir de gestão tripartite com definição dos papeis dos entes federados e } \\
\text { demais parceiros (Sistema S, bancos oficiais, IFETS, entre outros) }\end{array}$ \\
\hline Centro-Oeste & $\begin{array}{l}\text { - Mapeamento das potencialidades territoriais de Goiás baseado no modelo francês Anaconda } \\
\text { - Criação de um grupo de trabalho para criação de políticas de desenvolvimento a partir da } \\
\text { exonomia criativa }\end{array}$ \\
\hline Sudeste & $\begin{array}{l}\text { - Mapeamento de territórios, cidades e bairros potencialmente criativos a partir de definição } \\
\text { de critérios e ações de reconhecimento e visibilidade, incentivos, intercâmbios e trocas de } \\
\text { experiências como o da Teia dos Pontos de Cultura } \\
\text { - Recuperação e requalificação dos territórios a partir do fomento à economia criativa, a exem- } \\
\text { plo dos centros das cidades degradados }\end{array}$ \\
\hline Sul & $\begin{array}{l}\text { - Mapear os territórios existentes, a exemplo de Curitiba (Instituto Municipal de Administração } \\
\text { Pública) que realiza o mapeamento de bairros }\end{array}$ \\
\hline
\end{tabular}

Fonte: Minc (2011, p. 63).

Apesar da tentativa de levar a cultura e a economia criativa para um papel transversal de desenvolvimento econômico através das estratégias macroeconômicas e microeconômicas (Fluxograma 2) e de uma visão de integração com diversos ministérios (Fluxograma 1 e Quadro 1) e regiões (Quadro 2), inserindo a economia criativa a um posto de protagonismo para o desenvolvimento brasileiro, a SEC acabou por sofrer com a turbulência vivida no Ministério da Cultura, durante o período de 2011 até 2015. Com as transições das gestões Ana de Holanda, que a criou em 2011, a secretaria perdeu forças na gestão seguinte, de Marta Suplicy 2012-2014, que já não dialogava muito com a SEC e apostou suas fichas no desenvolvimento da política cultural assistencialista do Vale-Cultura, e posteriormente com Juca Ferreira, em 2015, que extinguiria por vez a SEC de dentro da estrutura do MinC. Desse modo, este período de 2011 até 2014 e, principalmente, a proposta do Plano Brasil Criativo são os maiores legados brasileiros em questão de uma tentativa de estruturação de uma política nacional de desenvolvimento econômico através da economia criativa. Através do Fluxograma 2 fica demonstrado, pelo vetor macroeconômico, 
Fluxograma 2 - A economia criativa brasileira e seus vetores e eixos de atuação

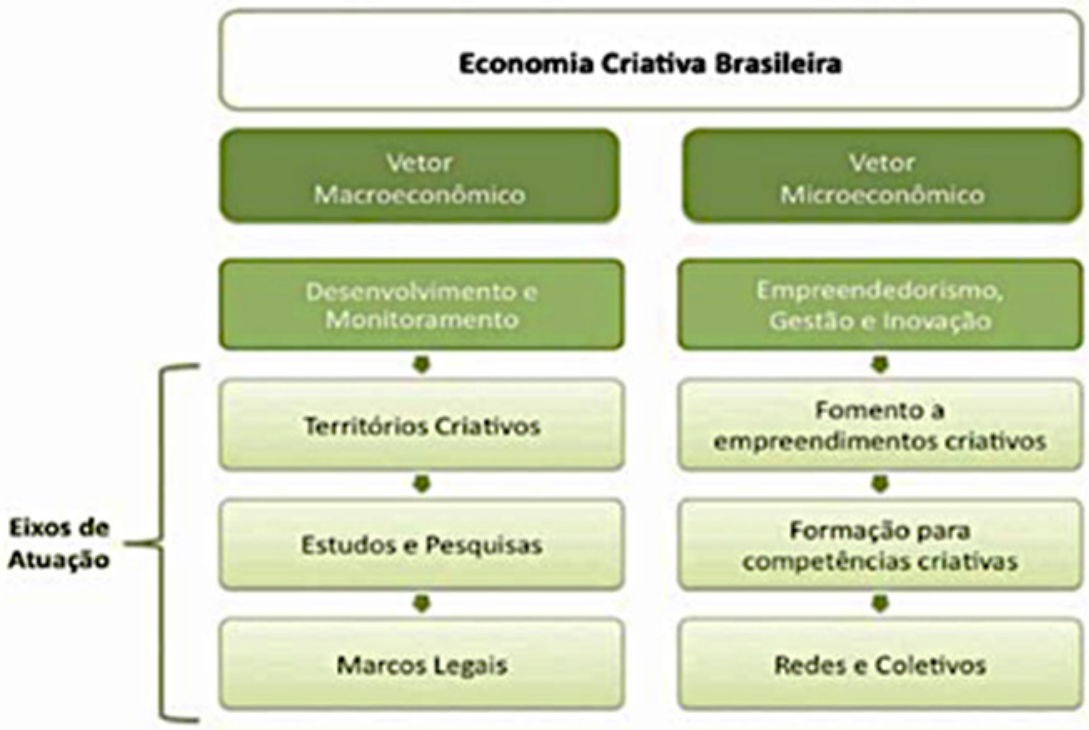

Fonte: MinC (2011, p. 43).

que o desenvolvimento dos "Territórios criativos" é considerado um dos principais eixos para a implementação e o desenvolvimento da economia criativa no Brasil.

Nos anos seguintes, desde o impeachment da presidente Dilma Rousseff, em maio de 2016, o campo da cultura no Brasil tem sofrido sérios ataques e retaliações.

A exclusão do MinC foi uma das primeiras realizações feitas pelo presidente Jair Bolsonaro, o que rebaixou a pasta ministerial a uma secretaria especial dentro do Ministério da Cidadania, para ser logo após novamente transferida para o Ministério do Turismo. Desde então, a secretaria tem um papel de coadjuvante dentro das estratégias de governo do então presidente e é um dos principais alvos de ataques dele. Esse cenário demonstra o completo desinteresse no desenvolvimento de políticas no campo da cultura e da economia criativa, transformadas em um mero indicador econômico e uma estratégia sem grande princípio de desenvolvimento e fundamento.

Com todos esses dados apresentados, pode-se analisar, então, que o Brasil, com toda a riqueza da sua diversidade cultural, sua economia estabilizada, setores criativos identificados e poder criativo das pessoas que aqui vivem, poderia estabelecer, como setor responsável pela competitividade de nossa indústria, a economia criativa, como um forte setor a ser desenvolvido, explorado, implementado e estimulado pelo nosso governo, pelo setor privado e pela sociedade civil. Assim, poderia ser 
possível estimular também as práticas ao desenvolvimento criativo; proporcionar melhorias inovadoras e culturais para a população; conseguir, além do fortalecimento econômico, o desenvolvimento intelectual e a qualidade de vida; enfim, demonstrar que o hibridismo e a maleabilidade das culturas, existentes no Brasil, são fatores positivos de inovação. Entretanto, como vivemos períodos sombrios dentro do campo da cultura, esse pensamento otimista dentro de uma estratégia nacional parece estar distante, o que coloca o Brasil novamente alguns passos atrás na corrida por um desenvolvimento social inclusivo e potencial.

Infelizmente, a Secretaria de Economia Criativa também não existe mais, porém, a questão de trabalhar a inclusão social faz-se evidente para um melhor desenvolvimento dentro dos espaços urbanos, em que o turismo pode ser o principal vetor para atingir esse feito, indo além da promoção de determinada territorialidade, de modo a buscar trabalhar e dialogar com todas as classes e não somente estabelecer um vencedor perante os demais, como Richard Florida deixa evidente em seus trabalhos. É sempre necessário questionar sobre a ascensão ou segregação das teorias de desenvolvimento de um território criativo.

\section{Conclusão}

A criatividade de uma cidade (i.e., de seus habitantes), mesmo que não descoberta ou não muito utilizada a seu favor por alguns gestores e administradores urbanos, possui um potencial de transformação, desenvolvimento e geração de emprego muito forte e interessante. Essa potencialidade é capaz de estimular se- tores econômicos, desenvolver a economia e gerar reconhecimento e prestígio para a cidade, o que ajuda também no progresso de outros setores e na conexão e melhoria dos espaços públicos valorizados pela população.

O que uma cidade precisa para se tornar cada vez mais criativa é, além de estimular suas manifestações criativas/culturais, melhorar o desenvolvimento de políticas de incentivo e atrair investimentos dos empresários e indústrias locais. Dessa maneira, pode-se começar a buscar e desenhar uma estratégia real de planejamento para os territórios criativos, a partir da compreensão de que um cluster criativo é um local onde as próprias práticas culturais são a principal forma de desenvolvimento econômico e resgate de identidade e vivência. Em outras palavras, uma cidade que direciona sua oferta à prática do lazer, turismo e tempo livre pode, ao mesmo tempo, ser um local de trabalho, desenvolvimento, produção e inovação.

Assim, quando uma territorialidade emerge na busca por uma proposta de se tornar criativa, ela deve valorizar suas singularidades, que podem se manifestar das mais variadas maneiras, destacando uma nova imagem e gerando inclusão. Porém, mesmo adotando todas essas perspectivas e evidenciando o poder de inclusão da EC (Economia Criativa) dentro da narrativa do desdobramento de uma cidade criativa, um olhar preocupante também faz acender um alerta, o de que as cidades passariam a "[...] obter sucesso e prosperar no sentido econômico, as regiões precisam oferecer os 3 Ts do desenvolvimento econômico. Se forem incapazes disso, ficarão ainda mais para trás" (Florida, 2002, p. 266). Afinal, o desdobramento de territórios criativos, seria, então, uma estratégia inclusiva ou continuaria a segregar? 
É com essa questão final que este artigo visa a provocar todos os agentes culturais, criativos, da área de turismo e gestores de políticas públicas das cidades, a pensarem nas melhores formas de desenvolver e implementar ações inovadoras para os territórios das cidades brasileiras. Trata-se de promover nossas singularidades culturais, mas também de conseguir estabelecer um desenvolvimento benéfico para todos, isto é, desde o meio ambiente até a economia da cidade e dos seus cidadãos. 0 turismo mais a economia criativa, utilizados e implementados de formas conscientes, podem ser esses grandes catalisadores para o desenvolvimento inclusivo e criativo do Brasil nas próximas décadas.

\section{[1] https://orcid.org/0000-0002-6445-5157 [1]}

Universidade Federal do ABC, Bacharelado em Políticas Públicas, Programa de Pós-Graduação em Políticas Públicas. São Bernardo do Campo, SP/Brasil.

souza.caio@ufabc.edu.br

\section{[II] https://orcid.org/0000-0002-2351-7200}

Universidade Federal do ABC, Bacharelado em Planejamento Territorial, Programa de Pós-Graduação em Planejamento e Gestão do Território. São Bernardo do Campo, SP/Brasil. gerardo.silva@ufabc.edu.br

\section{Notas}

(1) "This culturalization of the economy has not occurred naturally, of course; it has been carefully coordinated via agreements on trade and intellectual property, such as GATT (General Agreement on Tariffs and Trade) and the WTO (World Trade Organization), laws controlling the movement of mental and manual labor (i.e., immigration laws), and so on. In other words, the new phase of economic growth, the cultural economy, is also political economy" (Yúdice, 2003, p. 51).

(2) Como definição de cultura, vamos adotar a visão de Bauman (2013, p. 13), que compreendia a cultura como "[...] um acordo planejado e esperado entre os detentores do conhecimento (ou pelo menos acreditavam nisso) e os ignorantes (ou aqueles assim descritos pelos audaciosos aspirantes ao papel de educador); um acordo apresentado, por incidente, com uma única assinatura, unilateralmente endossado e efetivado sob a direção exclusiva recém-formada da 'classe instruída', que buscava o direito de moldar uma 'nova e aperfeiçoada' ordem a partir das cinzas do ancien régime. A intenção declarada dessa classe era a educação, o esclarecimento, a elevação e o enobrecimento de le peuple recém-entronizado no papel de citoyen do recém-criado État-nation, aquela junção de nação recém-formada que se alçava à condição de Estado soberano com o novo Estado que aspirava ao papel de curador, defensor e guardião da nação". 
(3) "O city marketing é entendido como um "[...] mecanismo institucional de promoção e venda das cidades" (Sánchez, 1994, p. 298). Ele é definido como a percepção das vantagens da obtenção de investimentos privados e da preparação de estruturas de parceria para alcançá-los. O city marketing será tratado aqui como o processo mediante o qual as atividades urbanas estão o mais proximamente possível relacionadas com a demanda de clientes-alvo de forma a maximizar a eficiência social e o funcionamento da área envolvida de acordo com todos os objetivos que tenham sido estabelecidos (Ashworth e Voogd, 1991, p. 11, apud Sánchez, 2010, p. 55).

(4) “A gentrificação tem se inserido nos discursos de planejamento das agendas de política urbana para melhorar o panorama econômico, físico e social de locais centrais 'desinvestidos' das cidades ao redor do mundo. Muitas vezes disfarçada como 'regeneração', 'renascença', 'revitalização' ou 'renovação', a gentrificação se tornou [...] 'uma estratégia global' e 'a 'expressão consumada de um urbanismo neoliberal emergente'” (Lees, Slater e Wyly 2008, p. xxi).

(5) A passagem do termo "indústrias culturais" para o termo "indústrias criativas" aponta para uma nova tentativa de articulação entre os domínios da arte ou cultura, da tecnologia e dos negócios, porém agora com pretensões de salientar os aspectos positivos dessa configuração (Bendassoli et al., 2009, p. 15).

(6) “[...] Cluster é um agrupamento geograficamente concentrado de empresas inter-relacionadas e instituições correlatas numa determinada área vinculada por elementos comuns e complementares". Porém o conceito de cluster criativo diferencia-se um pouco da definição usada por Porter, devendo ser entendido de forma mais holística e conciliadora de aspectos culturais, econômicos e sociais" (Porter, 1999, pp. 211-212 apud Reis e Urani, 2011, p. 37).

(7) Muito além da alegria e do samba no pé que factualmente estão vinculados à imagem e ao imaginário em torno do brasileiro, a cultura que nos envolve, a cada batuque em caixinha de fósforo que pode desencadear uma grande roda de samba ou ao garoto que, no meio de uma calçada apertada, decide improvisar um repente, demonstra que a cultura e a criatividade podem ser fatores determinantes para o desenvolvimento socioeconômico inclusivo do Brasil.

(8) Além da menção de território criativo, proposto pelo MinC no Plano da Secretaria de Economia Criativa, os autores deste artigo reconhecem, como território criativo, a definição de Closs et al. (2014, p. 13), que sintetiza que “A expressão 'território criativo' refere-se a bairros, cidades, estados de uma federação, regiões ou polos que apresentam potenciais culturais criativos e aliam preservação e promoção de valores culturais e ambientais na busca de um desenvolvimento integral e sustentável. Numa concepção mais ampla, um território criativo refere-se a um espaço ocupado por manifestações criativas materiais e simbólicas, que integra pessoas que vivem como residentes, comerciantes, produtores, consumidores ou frequentadores".

(9) Vale ressaltar que o PBC e as ações do SEC foram realizados entre o período de 2011 e 2013, sendo a Copa do Mundo de 2014 e os Jogos Olímpicos do Rio de Janeiro de 2016 importantes vetores para a implementação de ações e políticas públicas de estímulo ao desenvolvimento dos territórios criativos no Brasil. 


\section{Referências}

BAUMAN, Z. (2013). A cultura no mundo líquido moderno. Rio de Janeiro, Zahar.

BENDASSOLLI, P. F. et al. (2009). Indústrias criativas: definição, limites e possibilidades. ERA. São Paulo, v. 49, n. 1, pp. 10-18. Disponível em: http://www.scielo.br/pdf/rae/v49n1/v40n11a03. pdf. Acesso em: 13 jul 2021.

CLOSS, L. et al. (2014). Das cidades aos territórios criativos: um debate a partir das contribuições de Milton Santos. In: XXXVIII ENCONTRO DA ANPAD. Anais... Rio de Janeiro, 13-17 set. pp. 1-15.

EUROPEAN UNION (2013). European Capitals of Culture: success strategies and long-term effects. Directorate-general for Internal Policies. Policy Department. European Parliament.

(2021). European Capitals of Culture. Disponível em: :<https://ec.europa.eu/culture/policies/ culture-cities-and-regions/european-capitals-culture>. Acesso em: 13 jul 2021.

FIRJAN (2012). Indústria criativa: mapeamento da indústria criativa no Brasil. Rio de Janeiro, Sistema Firjam.

FLORIDA, R. (2002). A ascensão da classe criativa. Porto Alegre, L\&PM.

FRÚGOLI JUNIOR, H. (2000). Centralidade em São Paulo: trajetórias, conflitos e negociações na metrópole. São Paulo, Cortez/Edusp.

FURTADO, R. F. d'A. (org.) (2012). Ensaios sobre cultura e o Ministério da Cultura / Celso Furtado. Rio de Janeiro, Contraponto e Centro Internacional Celso Furtado (Arquivos Celso Furtado, v. 5).

HARVEY, D. (2001). A produção capitalista do espaço urbano. São Paulo, Annablume.

LEES, L.; SLATER, T.; WYLY, E. (2008). Gentrification. Londres, Routledge.

LEITÃO, C.; MACHADO, A. F. (2016). Por um Brasil criativo: significados, desafios e perspectivas da economia criativa brasileira. Belo Horizonte, Código.

MinC - Ministério da Cultura (2011). Plano da Secretaria de Economia Criativa: políticas, diretrizes e ações 2011-2014. Brasília, Minc. Disponível em: https://garimpodesolucoes.com.br/wp-content/ uploads/2014/09/Plano-da-Secretaria-da-Economia-Criativa.pdf. Acesso em: 13 jul 2021.

PORTER, M. (1999). Clusters e competitividade. HSM Management, v. 3, n. 15, pp. 100-110.

PUGA, F. P.; CASTRO, L. B. de (orgs.) (2018). Visão 2035: Brasil, país desenvolvido: agendas setoriais para alcance da meta. Rio de Janeiro, Banco Nacional de Desenvolvimento Econômico e Social.

PWC - Pricewaterhouse Coopers (2017). Global entertainment and media outlook 2017-2021. Disponível em: https://www.pwc.com.br/pt/outlook/2017/pwcoutlook201ffull-050917-lo2.pdf. Acesso em: 13 jul 2021.

REIS, A. C. F.; KAGEYAMA, P. (orgs.) (2011). Cidades criativas: perspectivas. São Paulo, Garimpo de Soluções.

REIS, A. C. F.; URANI, A. (2011). “Cidades criativas: perspectivas brasileiras”. In: REIS, A. C. F.; KAGEYAMA, P. Cidades Criativas: perspectivas. Garimpo de Soluções, São Paulo, pp. 30-37.

SÁNCHEZ, F. (2010). A reinvenção das cidades para um mercado mundial. Chapecó/SC, Argos. 
SÁNCHEZ, J. A. (1994). "Globalização dos lugares: metropolização e modernidade". In: SANTOS, M. (org.). Fim de século e globalização. São Paulo, Hucitec-Anpur.

SANT'ANNA, M. (2017). A cidade-atração: a norma de preservação de áreas entrais no Brasil dos anos 1990. Salvador, Edufba.

SELDIN, C. (2017). Imagens urbanas e resistências: das capitais de cultura às cidades criativas. Rio de Janeiro, Rio Books.

UNCTAD - UNITED NATIONS (2018). Creative economy outlook: trends in international trade in creative industries 2002-2015. Country Profiles: 2005-2014. UNCTAD.

UNESCO (2013). Creative economy report. Special edition: widening local development pathways. Paris/França, Unesco.

VIVANT, E. (2012). O que é uma cidade criativa? São Paulo, Editoria Senac.

YÚDICE, G. (2003). The Expendiency of Culture: uses of culture in the global era. Durham e Londres, Duke University Press.

Texto recebido em 28/mar/2021

Texto aprovado em $2 / \mathrm{jul} / 2021$ 